\title{
Chapter 35 Roadmaps for Future ICT Use in the Health Sector
}

\author{
Maria Teresa Borges Tiago \\ University of the Azores, Portugal \\ Flavio Tiago \\ University of the Azores, Portugal
}

\begin{abstract}
This chapter acts as both a review and an empirical framework analysis piece. It argues that technological acceptance and adoption by healthcare firms still suffers from oversimplification of its development, and specially, it measurement processes. There is a common thought both in business and academia that the technology adoption process is a key component of success and allows firms to achieve and sustain competitive advantages. In a digital era, these advantages arise from the potential of information and communication technology to improve firms' daily activities. This research tries to reinforce the assessment of ICT impacts on healthcare firm performance, presenting a set of induced and intangible benefits besides the traditional financial benefits, as well as measuring IS integration impact. To do so, a structural equation model is applied to a large database sample covering firms from 17 European countries. The results reinforce the importance of induced and structural benefits in firms' overall performance. It also found a positive relationship between IS integrated systems and performance. These results can be a starting point for a rethinking of the measurement models used in healthcare firms, and reinforce the argument stating that an IS integrated approach can provide better outcomes. Nevertheless, some questions remain unanswered regarding the impacts of ICT acceptance process on overall benefits, and therefore, future research will focus on this domain.
\end{abstract}

\section{INTRODUCTION}

Efforts from current research have been made to determine the role of Information and Communication Technologies (ICTs) at the firm level (Pilat, 2004; M.T.B. Tiago, Couto, Tiago, \& Vieira,
2008), the industry level (Inklaar, O’Mahony, \& Timmer, 2005; Pilat, 2004; Van Ark, Inklaar, \& McGuckin, 2003), and the macroeconomic level (Colecchia \& Schreyer, 2002; Van Ark, et al., 2003). From the different results, the impact of ICT can be perceived as detailed in (1) the con-

DOI: $10.4018 / 978-1-4666-3990-4 . c h 035$ 
tribution of ICT investment to capital intensity; (2) the contribution of the TOE model on a firm's performance; (3) the spillovers of rapid innovation by the use of ICT; (4) the competitive and dynamic effects of ICT on a firm's turbulence in terms of entry, exit, and the mobility of market shares of incumbents; and (5) the empowerment of strategic dimensions through the use of ICT tools.

ICT-related sectors are often characterized as high-tech and knowledge-intensive industries, since they rely deeply on the use of ICT tools to leverage an internal innovation process. When approaching other service sectors, the impacts of ICT adoption are perceived as lower (Chang, 2007). There has been much discussion of the role that recent advances in ICTs could play in improving health service systems in developing countries, as well as other services industries with traditionally lower levels of technology.

Drawing on the existing literature, this chapter attempts to analyze the impacts of ICT in health services firms' performance in European countries. Therefore, a conceptual model was developed for understanding and investigating the different contributions achieved by the adoption of ICT in this sector.

The data used in this research came from the 2006 e-business watch survey, covering 834 health services firms in a total of 17 countries (Belgium, Bulgaria, Czech Republic, Denmark, Finland, Greece, Spain, France, Hungary, Ireland, Italy, Latvia, The Netherlands, Norway, Poland, Sweden, and the UK).

In general, our findings support the conceptual framework presented and the results obtained can be used as a support tool in ICT decision makers' processes, since it clearly states the overall benefits of ICT successful implementation as well as presents the global performance impacts achieved with an integrated IS framework. Some useful preliminary insights are produced, however, leaving a considerable number of issues for future research, including the possibility of extending the research to include new tools and perspectives.

This chapter is organized in the following manner. The next section summarizes the literature related to the adoption of ICT tools by healthcare firms. The third section of the chapter formalizes the major points presented in the conceptual model and translates them into hypotheses. In the fourth section, the methodology is applied and the results are presented. The fifth section offers concluding remarks about the some of the major issues, controversies, and problems, as well as suggests solutions and future research paths.

\section{BACKGROUND}

In the mid-1980s, information and communication technologies have achieved a dominant role, leading to several changes in the internal organizational environment regardless of the sector of activity. In today's competitive global context, they act as an imperative for reducing the uncertainties relating to production and services processes, as well as supporting administrative tasks (Dewett \& Jones, 2001) and subsequent achievement of sustainable competitive advantage (McKee, Varadarajan, \& Pride, 1989).

A review of the existing literature related to information and communication technologies and IS impacts on organizational performance may enable a more effective implementation of these tools and how organizations can take advantage of their application (Eder \& Igbaria, 2001). However, even though there remains considerable interest in the relationship, the body of work that focuses on the contributions of technology on organizational performance could be enlarged (Eder \& Igbaria, 2001; Pae, Kim, Han, \& Yip, 2002; Maria Teresa Borges Tiago, Couto, Tiago, \& Vieira, 2007; 
17 more pages are available in the full version of this document, which may be purchased using the "Add to Cart" button on the product's webpage: www.igi-global.com/chapter/roadmaps-future-ict-use-health/78049

This title is available in InfoSci-Books, InfoSci-Medical, Communications, Social Science, and Healthcare. Recommend this product to your librarian: www.igi-global.com/forms/refer-database-to-librarian.aspx?id=78049

\section{Related Content}

Securing Health-Effective Medicine in Practice: A Critical Perspective on User-Driven Healthcare Rupert Whitaker (2011). International Journal of User-Driven Healthcare (pp. 1-15). www.igi-global.com/article/securing-health-effective-medicine-practice/54018

Normal Science and Post-Normal Sciences

Elie Geisler (2010). Redesigning Innovative Healthcare Operation and the Role of Knowledge Management (pp. 46-55).

www.igi-global.com/chapter/normal-science-post-normal-sciences/36516

Research Essay: The Ethics of E-Health

Christopher C. Hood and Sarah Bougourd (2011). International Journal of E-Health and Medical Communications (pp. 82-85).

www.igi-global.com/article/research-essay-ethics-health/53822

Privacy Considerations for Electronic Health Records

Mary Kuehler, Nakeisha Schimke and John Hale (2013). User-Driven Healthcare: Concepts,

Methodologies, Tools, and Applications (pp. 1387-1402).

www.igi-global.com/chapter/privacy-considerations-electronic-health-records/73895 